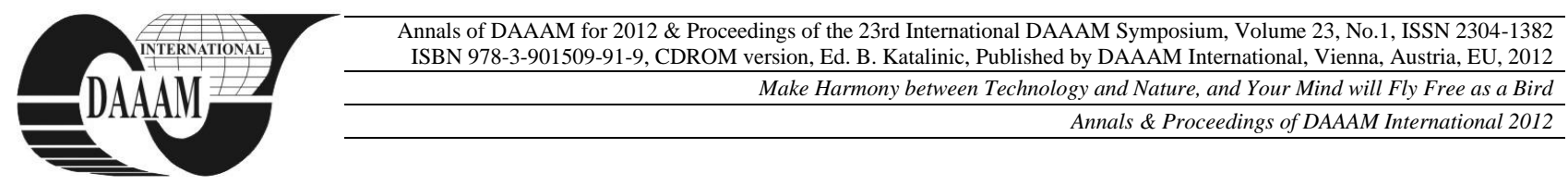

\title{
CONTROL OF A TWO AXES POSITIONING SYSTEM EQUIPPED WITH TWO STEP-BY-STEP ELECTRIC MOTORS
}

\author{
LIVINTI, P[etru] T.
}

\begin{abstract}
This work is presenting a two axes positioning system equipped with electrical step-by-step motors. For the study of the two axes positioning system an experimental stand has been built at the Electrical Machines Laboratory of the University "Vasile Alecsandri» in Bacau. The stand is composed of the following:A mechanical system on which the step-by-step electrical motors (MEPP) for driving the positioning mechanisms on the two axes are fixed, one driver for controlling the step-by-step motors, one voltage source $(0-30 \mathrm{~V}$ D.C.) for supplying the step-by-step motor driver, and one IBM P.C. compatible computer, equipped with the data acquisition board PCI 6251. For the control of the step-by-step motors, a program has been issued in the LabVIEW programming environment.
\end{abstract}

Keywords: positioning system, step-by-step electrical motor, data acquisition board

\section{INTRODUCTION}

The complexity of a positioning system is given by the number of the main motions it has to provide. The simplest positioning systems are those that position an object on a single axis because they need only one driving device for a good adjustment of it.The positioning systems on more axes are more intricate because a synchronization of the motion needs to be performed as well, in order to obtain a certain trajectory.

This work is presenting the positioning system of a cursor (in our case, of a writing instrument), on two axes (XY) by using step-by-step electric motors controlled from a computer through a data acquisition board, a driver and the program issued in the LabVIEW programming environment. The step-by-step motor is a synchronous, brushless electric motor that divides one revolution into a finite number of steps (incomplete rotations of constant angle). The step-by step motor is an electromechanical converter that transforms one train of digital pulses into a proportional motion of its shaft[1]. The angular position of the shaft can be precisely controlled without requiring an adjustment locked loop.

They are very often met in mechatronics, robotics, CNC machine tools, flexible systems etc. The motion of the rotor of the step-by-step motor consists of discrete, successive angular displacements of equal size that represent the motor steps. The number of the steps being performed should correspond to the number of the control pulses applied to the motor phases[2]. The total angular motion, composed of a number of steps equal to the number of control pulses applied to the motor phases, is determining the final position of therotor. This position is stored until a new control pulse is applied.
The univocity of the conversion pulses-motion associated to the memorising of the position are making from the step-by-step motor a good actuator, integrated to the position adjustment systems in open circuit. The step-bystep motor has also the feature to be able for getting into synchronism with the control pulses even from its still condition and running without slipping. Braking is also performed without going out of synchronism [3]. Due to this, starts, stops and sudden reversals are provided along the entire working range. The speed of a step-by-step motorcan be adjusted within large limits by modifying the frequency of the input pulses [4]. In other projects D.C. motors are used for building the positioning systems. These positioning systems require the usage of position encoders on each axis apart for assuring several position adjustment systems in locked loop. By using the step-by-step electric motors the costs for building a twoaxes positioning system are lower. At the same time, the control programs of the step-by-step motors used in positioning systems are much easier to be conceived and implemented in various industrial or didactic applications.

\section{DESCRIPTION OF THE EXPERIMENTAL STAND}

The experimental stand illustrated in Fig.1, used for the study of the two axes positioning system has been built at the Electrical Machine Laboratory of the University "Vasile Alecsandri" in Bacau and it is composed of:

a) Mechanical system for positioning on two axes

b) Control of the two axes positioning system

\subsection{Mechanical system for positioning on two axes}

The mechanical positioning system presented at Fig. 2 is composed of a metallic frame (1) to which a glass table (2) is fixed, of $52 \mathrm{~cm} / 48 \mathrm{~cm}$ size that has the role to support the paper sheet by means of four clips (3) [5]. This frame is also supporting the positioning system on the OX axis, composed of a step-by-step motor (4), guiding bars (5) of the cursor (6), cogged belt (7) that assures the transmission and sustaining frame (8). To the cursor of the $\mathrm{OX}$ axis positioning mechanism the sustaining frame (9) of the OY axis positioning mechanism is fixed. This is composed of the step-by-step motor (10), two metal guide ways for supporting the cursor, a cogged belt that assures the transmission and a writing instrument (11). 


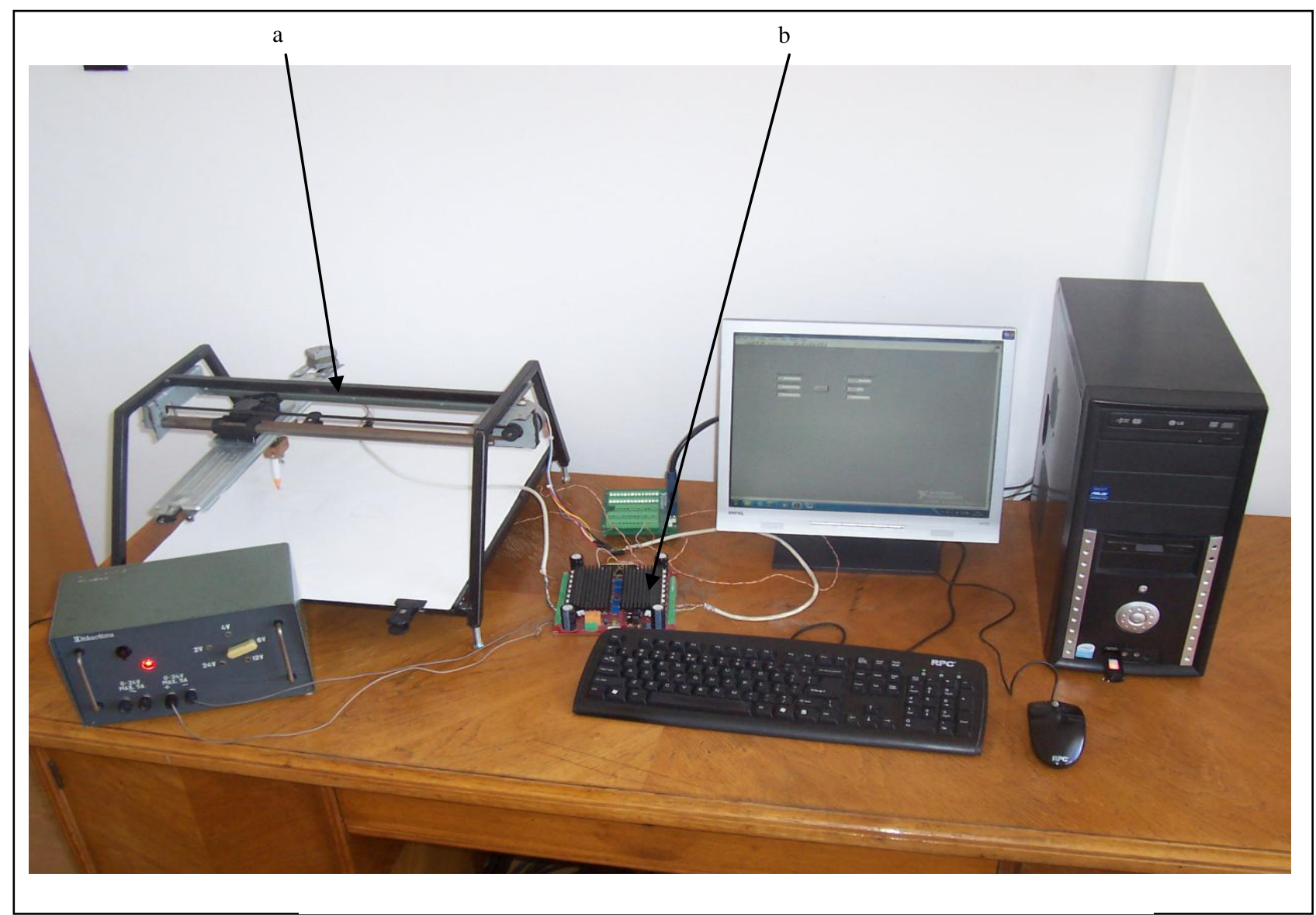

Fig.1. Picture of the experimental stand

\subsection{Control of the two axes positioning system}

The block diagram of the control system of the stepby step electric motors is shown at Fig. 3. The components of the control system are:

a) Step-by-step electric motors (MEPP).

b) Driver for the step-by-step motors.

c) Voltage supply source (0-24) V.D.C. for the step-bystep electric motors.

d) IBM PC compatible computer, equipped with PCI 6251data acquisition board, [6].

e) Connection coupling of the data acquisition board.

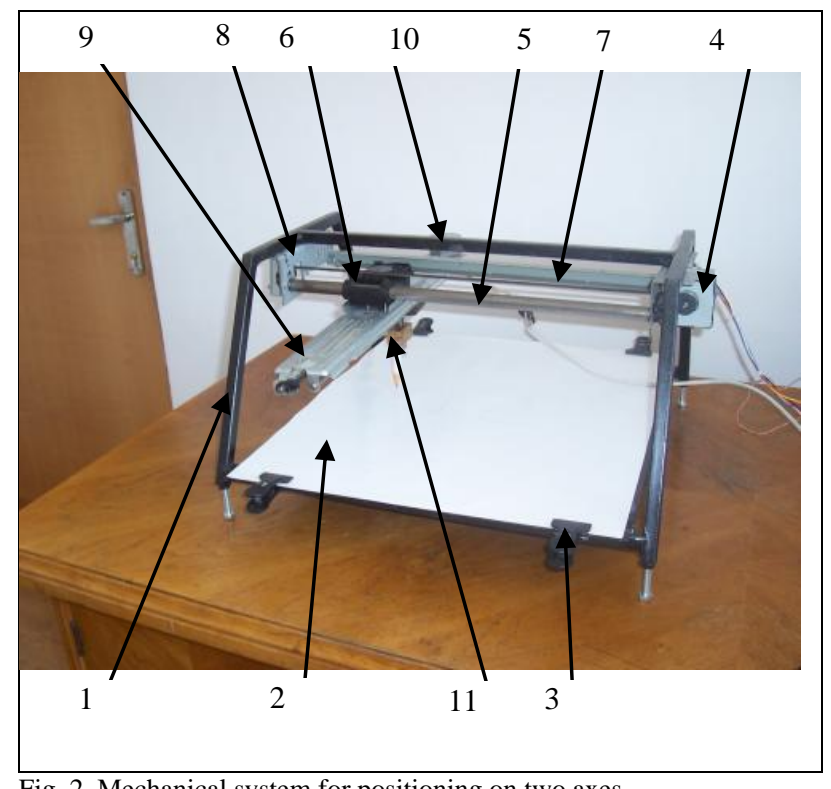

Fig. 2. Mechanical system for positioning on two axes
The characteristics of the equipment composing the structure of the experimental stand are:

a) Main parameters of the step-by-step electric motors:

1) Number of phases: $N_{f}=4$

2) Step angle: $\theta_{p}=3.6^{0}$

3) Number of steps per revolution: $N_{p} /$ rot $=100$

4) Phase current: $I_{f}=1[A]$

5) Phase resistance: $R_{f}=150[\Omega]$

6) Phase inductivity: $\mathrm{L}_{\mathrm{f}}=3.8[\mathrm{mH}]$

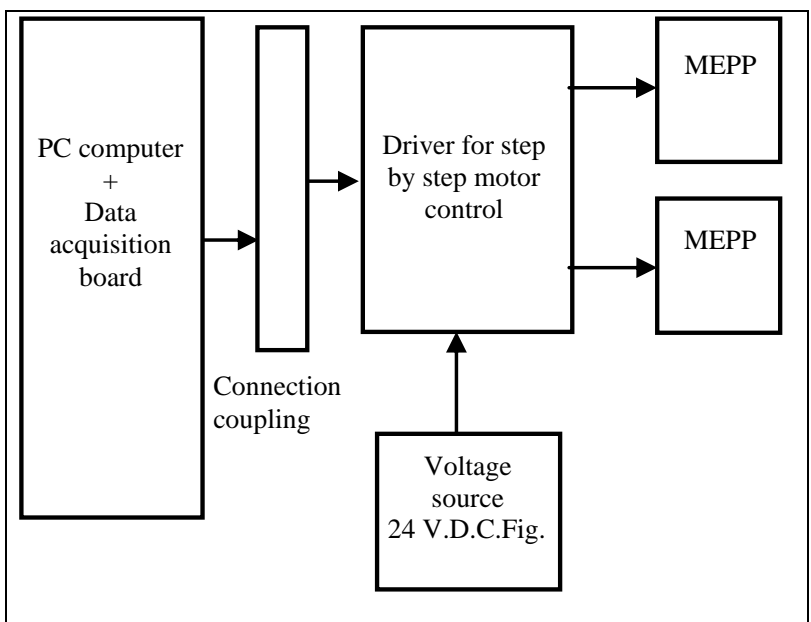

Fig.3. Block diagram of the experimental stand for controlling the stepby-step electric motors

7) Work voltage: $U_{f}=(12-24)[V]$

8) Torque: $\mathrm{M}=1.2[\mathrm{~N} \cdot \mathrm{m}]$

9) Motor weight: $\mathrm{G}=0.5 \mathrm{Kg}$ 


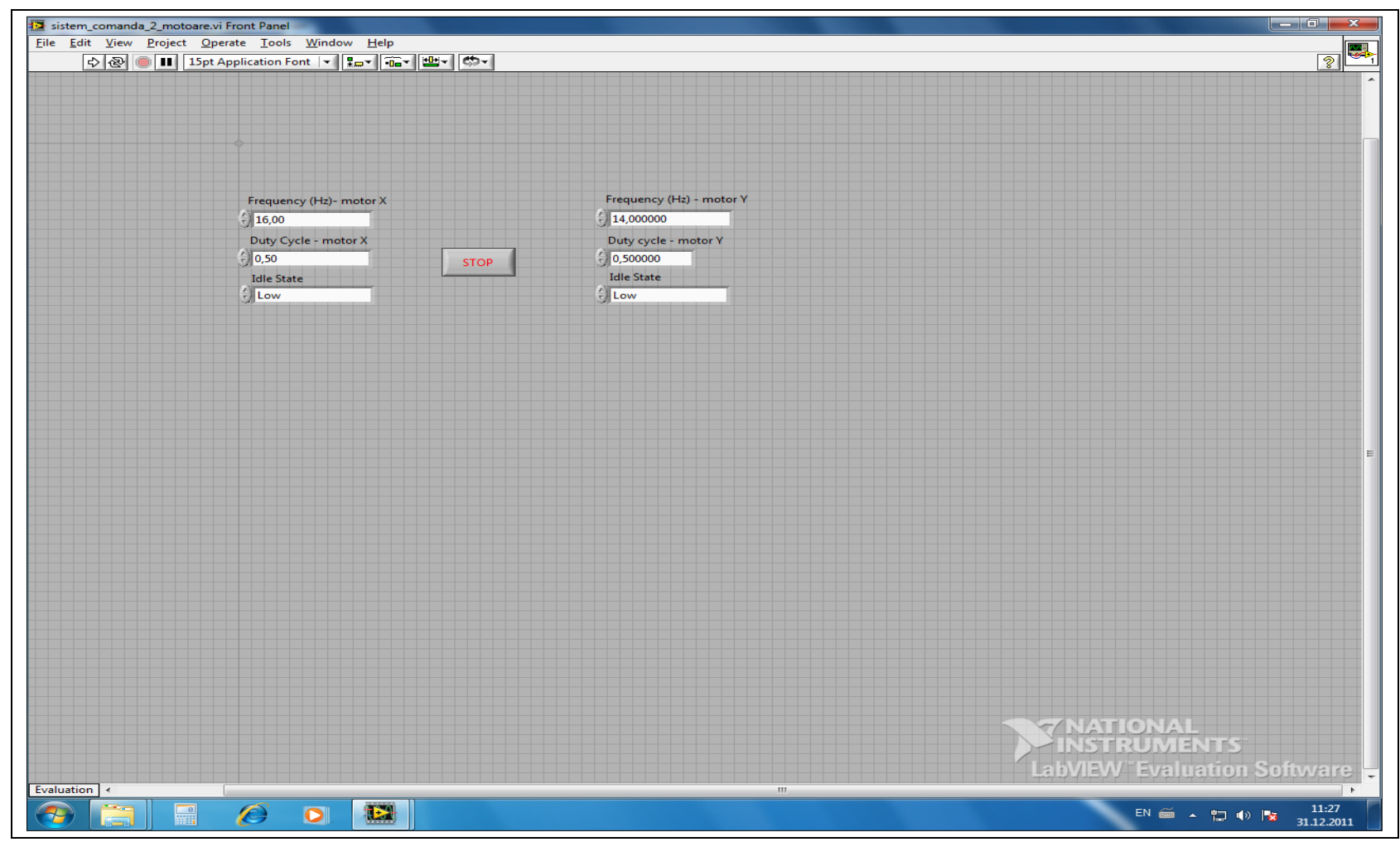

Fig. 4 Front panel

10) Shaft diameter: $\phi=10 \mathrm{~mm}$

b) The driver of the single pole step-by-step motors is equipped with a micro controller PIC 16F864 and has the following characteristics:

- Supply voltage: 40VD.C. maximum;

- Current: 5A maximum (software limited) for each motor;

- Stabilised voltage output: 5VD.C./100mA;

- Pulses for "Step": 35.000/second maximum;

- Minimum duration of the pulse for the "Step" input is $20 \mu \mathrm{sec}$

- Minimum duration after which the input "Dir" may be changed is $8 \mu \mathrm{sec}$;

- Relay output: 220 V/10A maximum;

- The input "Step" is active at the transition from "1" into "0" logic;

- The relay control is active when connected to "1" logic;

- It keeps the current constant into the motor for a constant torque;

- It runs with any program that may supply "Step/Dir" on the parallel port (LPT);

- Running mode: "Full Step/Half Step";

- Self diagnosis function;

- Error signalling.

c) The data acquisition board PCI 6251 has the following characteristics:

- analogue/numeric convertor on 16 bit;

- 16 analogue/numeric inputs;

- 2 numeric/analogue outputs;

- 24 digital inputs/outputs ;

- Range of input/output signals: \pm 10 VD.C.;

- Sampling rate: $833 \mathrm{kS} / \mathrm{s}$.
For controlling the step-by-step motors the digital outputs PFI 12/P2.4 have been used;

d) The IBM PC compatible computer has the following technical characteristics:

- Processor: Intel Pentium 4, 3 Ghz,

- Memory:1GB DDR2, Hard Disk 200 GB SATA, Optical unit:DVD+/-RW,

- Video board: nVIDIA GeFORCE 8400GS,

- Sound board: 6 Channels, Source: 450W.

\section{FUNCTIONING OF THE EXPERIMENTAL STAND}

Switch on the computer.For controlling the step-bystep motors a program has been issued in the LabVIEW programming environment [7]. The front panel of the virtual control device of the step-by-step electric motors is shown in Fig. 4 and the block diagram in Fig. 5. The control driver is supplied from the 12 V D.C. source[8].

The pulses generated by the data acquisition board PCI 6251 are applied on the "STEP" inputs of the control driver of each motor apart.

For changing the rotation direction the pulses generated by the data acquisition board will be also applied on the "Dir" input of the control driver. For modifying the rpm of the step-by-step electric motor various values will be given for the frequency of the control pulses generated by the data acquisition board on the front panel of the virtual control device.

The program allows the presetting of a certain number of steps by the electric drive motor. The LabVIEW program allows the simultaneous control of the step-by-step electric motors as well. 


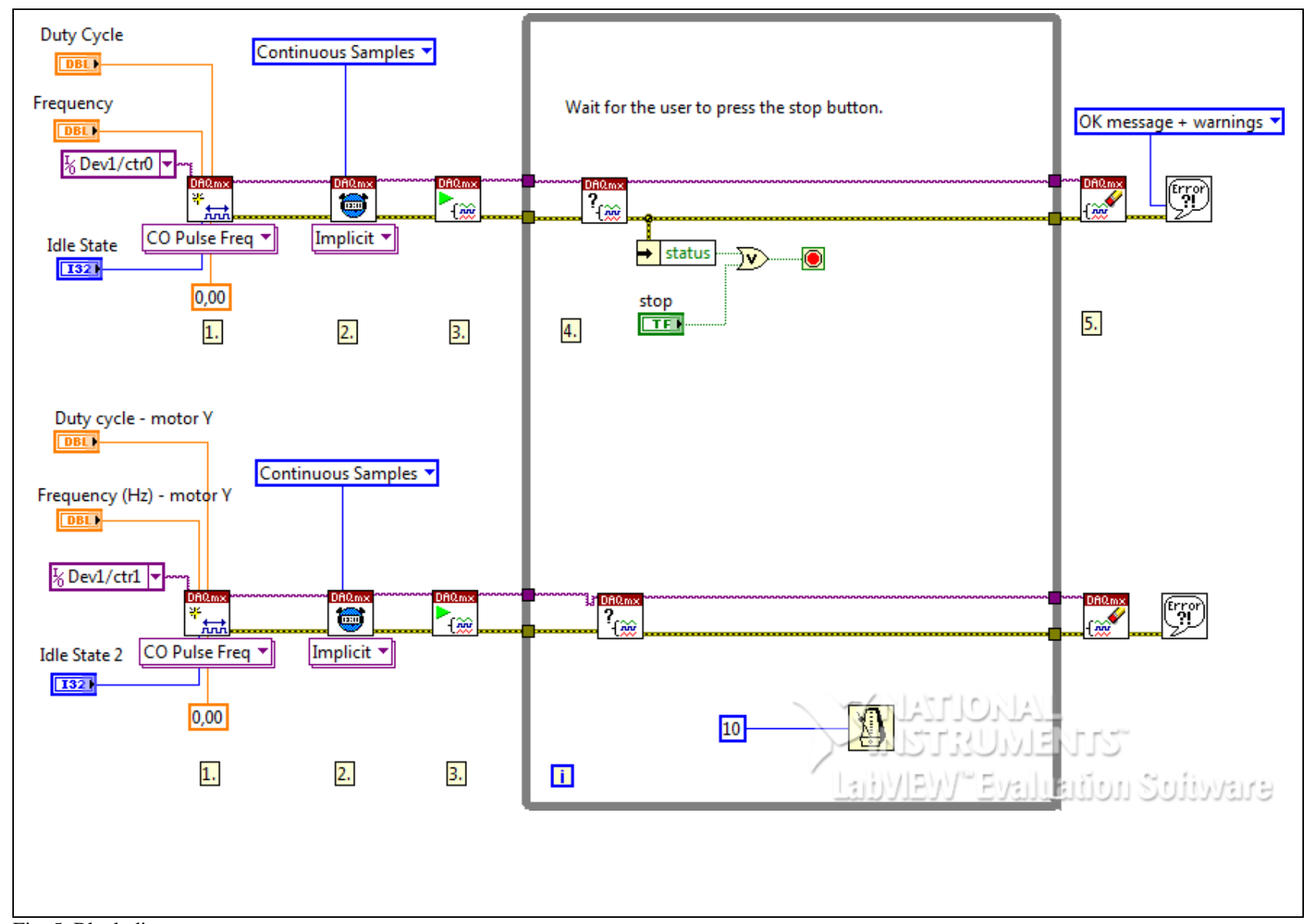

Fig. 5. Block diagram

\section{EXPERIMENTAL DETERMINATIONS}

The motion of the cursor containing the support for the writing device will be commanded to the origin position of the positioning system. A program will be issued for the motion of the writing device by a certain contour. In our case a program has been editedfor drawing two geometrical figures with the help of the writing device, a square and a triangle. The positioning accuracy of this system controlled on two axes complies with the limits required through the design data.

\section{CONCLUSIONS}

This work is presenting a positioning system on two axes equipped with electrical step-by-step motors. The experimental stand being used for the study of the two axes positioning system is composed of: a mechanical system of positioning, step-by-step electric motors (MEPP), a driver for controlling the step-by-step electric motors, a voltage source (0-24) V.D.C.for supplying the control driver of the step-by-step electric motors and an IBM PC compatible computer equipped with a data acquisition board PCI 6251.

For controlling the step-by-step motors a program has been issued in the LabVIEW programming environment. The positioning system is used for drawing geometrical figures in one plane. In perspective, researches may be continued for performing interpolation programs of the coordinates on two axes in the LabVIEW programming environment.

\section{REFERENCES}

[1] Kuo B. C., Kelemen A., Crivii M., Trifa V. (1981): Sisteme de comandă si reglare incrementală a pozitiei (Incremental Motion Control and Regulation Systems). Editura Tehnică Bucuresti

[2] Topa I., Dănilă A., Diaconu L. (2005) : Elemente de executie electrice (Electric Actuating Elements).Editura Matrix Rom, Bucuresti

[3] Bălută Gh. (2004): Actionări electrice de mică putere. Aplicatii. (Low Power Electric Drives. Applications).Editura Politehnium Iasi

[4] Trifa V. (1981) Servomecanisme / Servo-mechanisms. Printing Office of Polytechnic Institute of Cluj Napoca

[5] Radu O. (2012): Dissertation Thesis, "Vasile Alecsandri" University of Bacau, Romania

[6] Livinti P. \& Pusca R. (2009): Computerized System for Managing the Electricity Produced by Wind Power Stations, Sixth International Conference on Remote Engineering and Virtual Instrumentation - REV 2009, pp. 378-383

[7] LabVIEW, www.ni.com

[8] Puiu D. (2008): Sistem multi-ax pentru controlul pozitiei pe XY.(Multi-axis System for Position Control on XY) Conferinta Natională de instrumentatie virtuală. Bucuresti. (National Conference on Virtual Instrumentation, Bucharest) pp. 58-61 